\title{
Promote healing and anti-inflammatory and anti-bacterial activities of Jinjianling cream.
}

\author{
Wu Zhao, Ming-yang Qiu, Cui-xia Ma, Pei-han Gong, Yu-ting Liu, Ming-ming Yan*, Shuai Shao, Da- \\ qing Zhao
}

Changchun University of Chinese Medicine, Changchun 130117, People's Republic of China

\begin{abstract}
To study the healing effect and anti-inflammatory effect of Jinjianling cream on skin lesions, and to investigate the antibacterial activity, which proved that the preparation is safe and effective. The mouse scald model was established to observe the wound healing time and wound healing rate of mice, serum levels of TNF-á and IL-1 were measured by ELISA method. The model of eczema in mice was induced by DNCB, and the degree of ear swelling in mice was calculated. The hematoxylin-eosin (HE) staining was used to make pathological sections and count inflammatory cells, and the change of serum IL-2 level was determined by ELISA method. The bacteriostasis rate was determined by pour plate method, the diameter of inhibition zone (DIZ) was determined by filter paper diffusion method and the minimum inhibitory concentration (MIC) was determined by double dilution method. After treatment, the effect of Jinjianling cream groups on the healing of damaged skin in scalded mice was significant, the serum levels of TNF-a and IL-1 decreased, which were lower than those in the model group $(p<0.05, p<0.01)$. In the mouse eczema model, the degree of ear swelling improved significantly, serum IL-2 level was decreased, and inflammatory cell count was significantly than the model group $(p<0.05, p<0.01)$. The results of antibacterial experiments showed that bacteriostasis rate was positively correlated with drug concentration. The DIZ values of bacteriostatic circle on Staphylococcus aureus and Escherichia coli were $17.25 \mathrm{~mm}$ and $25.62 \mathrm{~mm}$, moreover, The MIC values of two kinds of bacteria all were $64 \mathrm{~g} / \mathrm{mL}$. Jinjianling cream can promote the healing ability of damaged skin and reduce inflammation of wound. It also has a strong inhibitory effect on wound pathogenic bacteria, can significantly improve wound healing and effectively treat dermatitis, eczema and other skin disease, and the relevant mechanisms need further study.
\end{abstract}

Keywords: Chinese medicine compound, Promote healing, Anti-inflammatory, Antibacterial

Accepted on January 29, 2018

\begin{abstract}
Abbreviations
ELISA: Enzyme Linked Immunosorbent Assay; TNF-á: Tumour Necrosis Factor-a; IL-1:Interleukin-1; IL-2:Interleukin-2; DNCB: 2,4-Dinitrochlorobenzene; HE: Hematoxylin-eosin; DIZ: Diameter of Inhibition Zone; MIC: Minimum Inhibitory Concentration; IC50: Half Maximal Inhibitory Concentration; Tris-base: Tris(hydroxymethyl)methyl aminomethane
\end{abstract}

\section{Introduction}

Skin is the largest organ of body, always involved in the body's functional activities, as the first physiological defence of human body, which protects various tissues and organs from physical, mechanical, chemical and pathogenic microbial invasion. Therefore, the skin bears the threats of multiple factors in vivo and in vitro, resulting in skin damage and causing various skin diseases. Scald as a common cutaneous lesion, the healing mechanism is related to many cytokines, including inflammatory cytokines interleukin-1 (IL-1), interleukin-6 (IL-6), etc. In addition, tumour necrosis factor-á (TNF-á) also plays an important role in the inflammatory response and participates in the whole process [1]. Atopic dermatitis $(\mathrm{AD})$ is a common recurrent inflammatory skin disease that frequently presents with symptoms such as itching, erythema and eczema, the skin will be damaged seriously, and resulting in inflammatory reaction including the release of inflammatory cytokines such as interleukin-2(IL-2), which plays an important regulatory role throughout the reaction $[2,3]$.

For the treatment of skin injury, ointment is widely used in modern medicine. Hu Anglian ointment as our school hospital preparation, the prescription comes from the classic "The Golden Mirror of Medicine", applied in clinical for many years, has been affirmed by the majority of patients. The study was based on prescription medicinal materials, including Coptis chinensis, golden cypress, turmeric, Chinese angelica and Rehmannia glutinosa, the innovation and optimization of preparation process were carried out, developed a kind of external preparations of traditional Chinese medicine. Through the establishment of mouse scald model and mouse eczema model, skin injury was investigated, then investigated antibacterial activity and antioxidant in vitro, in order to provide theoretical basis for the application and development of external preparations of traditional Chinese medicine. 


\section{Materials and Methods}

\section{Materials}

Sulfadiazine silver cream (H20057720) was bought from Kunming torch Pharmaceutical (Group) Co., Ltd.; Compound dexamethasone acetate cream (H44024170) was bought from Shenzhen China Resources Gosun Pharmaceutical Co., Ltd.; TNF-á, IL-1 and IL-2 were bought from BD, America; Escherichia coli strain (ATCC8739) and Staphylococcus aureus strain (ATCC6538) were purchased from Jilin University Laboratory; Stearic acid, monoglyceride, sodium lauryl sulfate were bought from Tianjin Guangfu Chemical Research Institute; ethyl paraben was bought from Tianjin Tiantai Fine Chemicals Co., Ltd. All other chemicals and reagents used in this study were of analytical grade.

\section{Animals}

BALB / c mice were purchased from Hongda Biological Technology Co., Ltd., The mice were 6 weeks old, all male. Animals were maintained under standard laboratory conditions with controlled temperature $\left(23 \pm 1^{\circ} \mathrm{C}\right), 12: 12 \mathrm{~h}$ dark/light cycle with free access to standard rodent food and water. The animals were treated in accordance with the current national guidelines on animal care and use.

\section{Extraction process}

According to result of the pre-experiment, we have optimized the optimum parameters of the extraction process, and designed the best extraction scheme. That is, Coptis chinensis $32.5 \mathrm{~g}$, Phellodendron $48.8 \mathrm{~g}$ and turmeric $48.8 \mathrm{~g}$, added with 10 times the amount of $70 \%$ ethanol to extract 3 times, each time $1 \mathrm{~h}$, the filtrate was collected, concentrated and dried, then prepare for mix. After the medicinal residue was dried, mixed with Angelica $32.5 \mathrm{~g}$ and Rehmannia glutinosa $195 \mathrm{~g}$, added with 8 times distilled water to extract 3 times, each time $1 \mathrm{~h}$, the filtrate was collected and concentrated to dryness, then the above extracts was crushed and mixed.

\section{Formability process}

Stearic acid $100 \mathrm{~g}$, monoglyceride $50 \mathrm{~g}$, white petrolatum and liquid paraffin $50 \mathrm{~g}$ were mixed, after heating to melt as the oil phase. In addition, $150 \mathrm{~g}$ of glycerin and $500 \mathrm{~mL}$ of distilled water were heated to $85^{\circ} \mathrm{C}$, added with $10 \mathrm{~g}$ of sodium lauryl sulfate and $2 \mathrm{~g}$ of ethylparaben to dissolve, then put the extracts in it and mixed well as the water phase. The water phase was added to the oil phase slowly, stirring at a constant speed to emulsification and condensation.

\section{Group and therapy of scald models}

24 hours before the experiment, the 100 mice were depilated with $10 \%$ sodium sulfide solution on the back, anesthetized by intraperitoneal injection of $1 \%$ pentobarbital $(0.5 \mathrm{ml} / 10 \mathrm{~g})$. The $50 \mathrm{~g}$ weight was placed in boiling water for 10 minutes, then placed on the back of the skin of mice for $8 \mathrm{~s}$, which the deep second degree scald model with an area of $2 \mathrm{~cm} \times 2 \mathrm{~cm}$ can be formed. The mice were randomly divided into five groups of twenty animals each $(n=20)$, as follows:

Model group: mice treated with $0.9 \%$ saline. Positive control group: mice treated

with compound sulfadiazine silver cream 0.1 g. Low dose group: equivalent $17.88 \mathrm{~g} / \mathrm{kg}$

dosage, mice treated with Jinjianling cream 0.1 g. Medium dose group: equivalent

$35.76 \mathrm{~g} / \mathrm{kg}$, mice treated with Jinjianling cream $0.1 \mathrm{~g}$. High dose group: equivalent

$71.52 \mathrm{~g} / \mathrm{kg}$, mice treated with Jinjianling cream $0.1 \mathrm{~g}$. Each group was dosed twice daily, continuous administration for 28 days. (Wound healing standards: the wound scab off and the new epithelial formation. 28 days unhealed was recorded for 28 days)Wound healing rate: 1,7,14,21 days after scald with a transparent sulfuric acid paper to describe the wound, cut and weigh, replacing area with quality. Wound healing rate $(\%)=($ Original burns area- the area that did not heal at each time point)/Original burns area $\times 100$ Cytokines: At 24 and 48 $\mathrm{h}$ after scalded, blood samples were obtained from the eyeball of 5 mice in each group, samples were centrifuged at 3500 $\mathrm{r} / \mathrm{min}$ for $15 \mathrm{~min}$, and the supernatant was taken at below minus 20 centigrade for preservation. The serum levels of TNF-a and IL-1 were determined by ELISA method, and the specific procedures were operated according to the kit instructions.

\section{Group and therapy of eczema model}

1 day before the experiment, the 60 mice were depilated with $10 \%$ sodium sulfide solution, then formed the area with area of $2 \mathrm{~cm} \times 2 \mathrm{~cm}$ on the back skin. After 24 hours, 7\% DNCB 100 iL was coated on the depilated skin of each mice for sensitization, sensitized once a day, continuing for 3 days, after 5 days, $0.1 \%$ DNCB $10 \mathrm{iL}$ were coated in the interior right ears to challenge and sensitize, once every 3 days, totally for 4 times (except for the blank group). Each time after stimulation of $24 \mathrm{~h}, 48 \mathrm{~h}$ and $72 \mathrm{~h}$, each group was coated with drugs in the Interior right ear of mice, administration in the morning and afternoon everyday. The

mice were randomly divided into six groups of ten animals $\operatorname{each}(n=10)$, as follows:

Blank group: mice treated with vehicle cream 0.1 g. Model group: mice treated with vehicle cream $0.1 \mathrm{~g}$. Positive control group: mice treated with compound dexamethasone acetate 0.1 g. Low dose group: (equivalent $17.88 \mathrm{~g} / \mathrm{kg}$ dosage), mice treated with Jinjianling cream $0.1 \mathrm{~g}$. Medium dose group: (equivalent $35.76 \mathrm{~g} / \mathrm{kg}$ dosage), mice treated with Jinjianling cream $0.1 \mathrm{~g}$. High dose group: (equivalent $71.52 \mathrm{~g} / \mathrm{kg}$ dosage), mice treated with Jinjianling cream $0.1 \mathrm{~g}$.

Swelling degree: 1 day of medication withdrawal after the end of the treatment, the mice were sacrificed by cervical dislocation. Tissues (holes with the diameter of $0.8 \mathrm{~mm}$ ) were punched at same positions on each ear by the puncher, weight difference between their left ears and right ears were 
Citation: Zhao W, Qiu MY, Ma C, et al. Promote healing and anti-inflammatory and anti-bacterial activities of Jinjianling cream. J

calculated. Inhibition $\operatorname{rate}(\%)=($ model group - drug group $) /$ model group $\times 100$

Cytokine: 1 day after medication withdrawal, blood samples were obtained from the eyeball of 5 mice in each group, samples were centrifuged at $3500 \mathrm{r} / \mathrm{min}$ for $15 \mathrm{~min}$, and the supernatant was taken at below minus 20 centigrade for Preservation. The serum levels of IL-2 were determined by ELISA method, and the specific procedures were operated according to the kit instructions. Inflammatory cell infiltration: 1 day after medication withdrawal, 5 mice in each group were randomly selected, and the right ear tissue was made into pathological sections, the number of infiltrating inflammatory cells was counted by $\mathrm{HE}$ staining, and the average was calculated [4].

\section{Antibacterial experiment in vitro}

Colony count: The experimental group was divided into low dose group (17.88 g/kg equivalent dose), medium dose group (equivalent $35.76 \mathrm{~g} / \mathrm{kg}$ dosage), high dose group (equivalent $71.52 \mathrm{~g} / \mathrm{kg}$ dosage). Each group was weighed with a specimen (cut into $1.0 \mathrm{~cm} \times 1.0 \mathrm{~cm}$ size), evenly coated with drug $0.1 \mathrm{~g}$, the sample was placed in $250 \mathrm{ml}$ triangle bottle, adding $70 \mathrm{~mL}$ PBS and $5 \mathrm{~mL}$ bacteria suspension respectively, that the concentration of bacterial suspension in PBS was $1 \times 10^{4} \sim 9 \times$ $10^{4} \mathrm{cfu} / \mathrm{mL}$. The conical flask was fixed on a shaker, $300 \mathrm{r} /$ min, shaking for $1 \mathrm{~h}$. The $0.5 \mathrm{~mL}$ sample solution was added to PBS for appropriate dilution and cultured with agar plate, then counted colony.

bacteriostasis $\operatorname{rate}(\%)=(\mathrm{A}-\mathrm{B}) / \mathrm{A} \times 100$

A represents the average number of colonies before shaking; B represents the average number of colonies after shaking.

Diameter of inhibition zone (DIZ) measurement: The filter paper was punched into a $5 \mathrm{~mm}$ diameter disc, and sterilized, poured into the appropriate amount sterilized medium(about 4 mm thick), maintained at a temperature of $45^{\circ} \mathrm{C}$, gently rotated the Petri dish, set aside to set the plate. The cultured bacteria were made into suspension with a certain concentration. $1 \mathrm{~mL}$ of the bacterial suspension was added to the sterilized Petri dish and daubed equably. The filter paper that coated with the quantitative drug $(0.1 \mathrm{~g})$ was placed on the surface of Petri dish. The culture dish was cultured at $37^{\circ} \mathrm{C}$ for $24 \mathrm{~h}$, and the diameter of inhibition zone was measured with vernier caliper [5].

Minimum inhibitory concentration (MIC) determination: The samples were diluted into a series of double concentration gradients $(0.5,1,2,4,8,16,32,64,128,256 \mathrm{ig} / \mathrm{mL})$ by double dilution method, the samples were added to the test tubes, which containing $10 \mathrm{~mL}$ medium, then added with $50 \mathrm{iL}$ of bacteria solution to each test tube and mixed thoroughly. All test tubes were cultured at $37^{\circ} \mathrm{C}$ for $24 \mathrm{~h}$, and maintained at the speed of $220 \mathrm{r} / \mathrm{pm}$ for shaking. The minimum concentration of invisible turbidity by naked eyes in the test tube was MIC [6].

\section{Results}

\section{Effect on scald model mice}

The healing performance of mice in each group was shown in Figure 1. All mice were cured within 28 days, the positive control group had the best healing effect, medium dose group and high dose group also had good therapeutic effect. The scalp on the back of the mice became smaller and smaller with time until disappeared, the exposed skin on the back began to grow new hair and became thick until covered the affected area. It was shown in Table 1 that, compared with model group, the healing rate and healing time of positive control group, medium dose group and high dose group had the significant difference $(\mathrm{p}<0.05, \mathrm{p}<0.01)$; and compared with positive control group, the difference of high dose group was not significant, that is consistent with the trend of healing in each group of mice as shown in Figure 2.
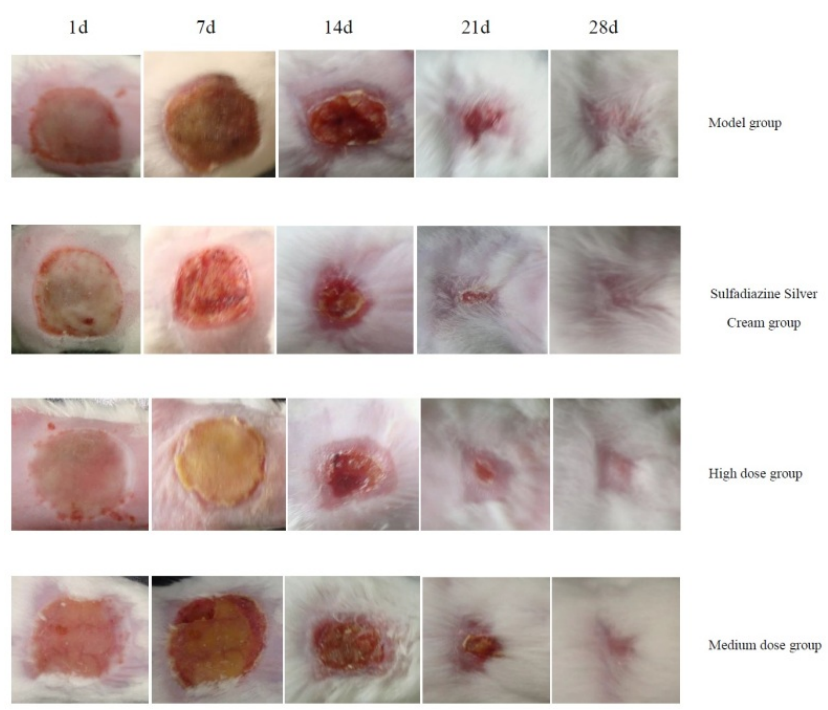

Figure 1: Wound healing performance of mice in differert groups. 


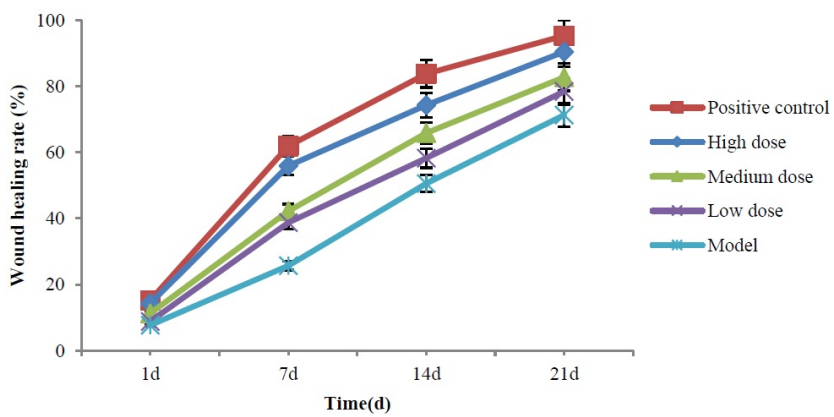

Figure 2: Wound healing rate of mice in different groups.

Table 1: Wound healing rate and healing time of mice in each group (Mean $\pm S D)$. ${ }^{*} p<0.05,{ }^{* *} p<0.01$ compared with model group

\begin{tabular}{|c|c|c|c|c|c|c|}
\hline \multirow[b]{2}{*}{ Group } & \multirow[b]{2}{*}{ Dose $(\mathrm{g} / \mathrm{kg})$} & \multicolumn{4}{|c|}{ Healing rate (\%) } & \multirow{2}{*}{ Healing time } \\
\hline & & $1 \mathrm{~d}$ & $7 d$ & $14 \mathrm{~d}$ & $21 \mathrm{~d}$ & \\
\hline Model & - & $7.68 \pm 8.25$ & $25.68 \pm 5.17$ & $50.57 \pm 6.32$ & $71.28 \pm 5.85$ & $27.14 \pm 2.47$ \\
\hline Positive control & - & $15.16 \pm 6.84^{*}$ & $61.84 \pm 7.26^{* *}$ & $83.78 \pm 6.93^{*}$ & $95.70 \pm 3.27^{\star \star}$ & $19.26 \pm 1.62^{\star *}$ \\
\hline Low dose & 1.788 & $8.79 \pm 2.32$ & $38.69 \pm 2.88^{*}$ & $58.21 \pm 3.58$ & $78.36 \pm 4.65$ & $24.87 \pm 2.18$ \\
\hline Medium dose & 3.576 & $11.21 \pm 2.87^{*}$ & $42.23 \pm 4.64^{*}$ & $65.84 \pm 9.12^{*}$ & $82.67 \pm 5.67^{*}$ & $22.65 \pm 1.94^{*}$ \\
\hline High dose & 7.512 & $14.28 \pm 3.68^{\star *}$ & $55.87 \pm 8.82^{* *}$ & $74.24 \pm 3.67^{* *}$ & $90.36 \pm 6.53^{\star *}$ & $18.12 \pm 2.36^{* *}$ \\
\hline
\end{tabular}

Cytokine changes of mice in each group were shown in Table 2. 24, $48 \mathrm{~h}$ after scald, compared with model group, the TNF-á level of positive control group and three dose groups decreased significantly $(\mathrm{p}<0.05, \mathrm{p}<0.01)$; and $48 \mathrm{~h}$ after scald, the IL-1 level of positive control group, medium dose group and high dose group decreased obviously, compared with model group, they had the significant difference $(p<0.05, p<0.01)$. The results showed that the Chinese medicine cream can inhibit the release of inflammatory mediators, reduce the inflammatory reaction of wound and promote wound healing.

Table 2: TNF- $\alpha$ and IL-1 level of mice in each group (Mean $\pm S D$ )

\begin{tabular}{|c|c|c|c|c|c|}
\hline \multirow[b]{2}{*}{ Group } & \multirow[b]{2}{*}{ Dose } & \multicolumn{2}{|l|}{ TNF-a(ng/L) } & \multicolumn{2}{|l|}{ IL-1(pg/L) } \\
\hline & & $24 \mathrm{~h}$ & $48 \mathrm{~h}$ & $24 \mathrm{~h}$ & $48 \mathrm{~h}$ \\
\hline Model & - & $545.18 \pm 70.14$ & $410.50 \pm 90.17$ & $2610.65 \pm 498.50$ & $2270.48 \pm 189.30$ \\
\hline Positive control & - & $400.28 \pm 89.21^{*}$ & $268.35 \pm 78.88^{*}$ & $2055.48 \pm 159.25^{*}$ & $1578.64 \pm 358.55^{\star *}$ \\
\hline Low dose & 1.788 & $461.20 \pm 65.68^{*}$ & $318.78 \pm 53.26^{*}$ & $2201.08 \pm 518.34$ & $1889.58 \pm 378.26$ \\
\hline Medium dose & 3.576 & $408.35 \pm 105.57^{*}$ & $305.86 \pm 110.28^{* *}$ & $2145.33 \pm 480.68$ & $1650.78 \pm 405.28^{*}$ \\
\hline High dose & 7.512 & $378.26 \pm 85.84^{* *}$ & $238.63 \pm 102.32^{\star *}$ & $2058.25 \pm 360.26$ & $1428.26 \pm 467.82^{* *}$ \\
\hline
\end{tabular}

\section{Effect on eczema model mice}

Ear swelling of mice in each group was shown in Table 3. Generally, degree of ear swelling was believed to reflect the reaction degree of the inflammation, compared with model group, the degree of ear swelling of positive control group and high dose group decreased significantly $(\mathrm{p}<0.01)$; and medium dose group could also improve the ear swelling of $\operatorname{mice}(\mathrm{p}<0.05)$.

Table 3: Degree of ear swelling of different mouse eczema model $($ Mean $\pm S D)$

\begin{tabular}{llll}
\hline Group & Dose $\mathbf{( g / k g )}$ & $\begin{array}{l}\text { Swelling degree } \\
(\mathbf{m g})\end{array}$ & Inhibition rate $(\%)$ \\
\hline Blank & - & $0.13 \pm 0.09$ & - \\
\hline Model & - & $12.87 \pm 0.58$ & - \\
\hline Positive control & - & $4.62 \pm 0.63^{* *}$ & $64.10 \pm 0.85$ \\
\hline Low dose & 1.788 & $9.21 \pm 0.27$ & $28.43 \pm 0.48$ \\
\hline Medium dose & 3.576 & $7.38 \pm 0.55^{*}$ & $42.65 \pm 0.58$ \\
\hline
\end{tabular}


Citation: Zhao W, Qiu MY, Ma C, et al. Promote healing and anti-inflammatory and anti-bacterial activities of Jinjianling cream. $J$ Pharmacol Ther Res 2018;2(1):17-23.

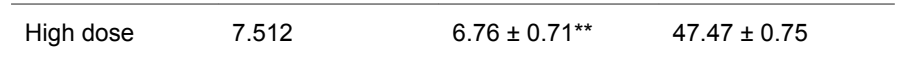

Cytokines and inflammatory cell changes of mice in different groups were shown in Table 4 . The results showed that positive control group, medium dose group and high dose group could significantly decreased the count of inflammatory cell $(\mathrm{p}<0.05$, $p<0.01$ ), and the effect of high dose group was better than positive control group. Compared with model group, the IL-2 level of positive control group, medium dose group and high dose group decreased significantly $(\mathrm{p}<0.05, \mathrm{p}<0.01)$.

Table 4: Cytokines and inflammatory cell of different groups (Mean \pm $\mathrm{SD}) * \mathrm{p} 0.05,{ }^{*} \mathrm{p} 0.01$ compared with model group

\begin{tabular}{llll}
\hline Group & Dose $(\mathbf{g} / \mathbf{k g})$ & IL-2 $(\mathbf{p g} / \mathbf{m L})$ & Cell count(n) \\
\hline Blank & - & $12.44 \pm 0.32$ & 0 \\
\hline Model & - & $33.25 \pm 0.28$ & $3.1 \pm 0.62$ \\
\hline
\end{tabular}

\begin{tabular}{llll}
\hline Positive control & - & $16.64 \pm 0.35^{\star *}$ & $1.9 \pm 1.25^{\star}$ \\
\hline Low dose & 1.788 & $28.82 \pm 0.74$ & $2.8 \pm 0.83$ \\
\hline Medium dose & 3.576 & $23.63 \pm 0.36^{\star}$ & $1.9 \pm 0.75^{\star}$ \\
\hline High dose & 7.512 & $20.35 \pm 0.83^{*}$ & $1.5 \pm 0.14^{\star *}$ \\
\hline
\end{tabular}

Pathological tissue of mice in each group was shown in Figure 3. Compared with blank group, the epidermis of model group thickened obviously, edema and vascular dilatation were formed. Meanwhile, a large number of lymphocytes infiltrated, that showed the model was built successfully. Edema symptoms of positive control group and each concentration group were relieved, the thickening degree of skin decreased obviously, the number of dermal lymphocytes decreased in different degrees.

\section{Blank group Model group}

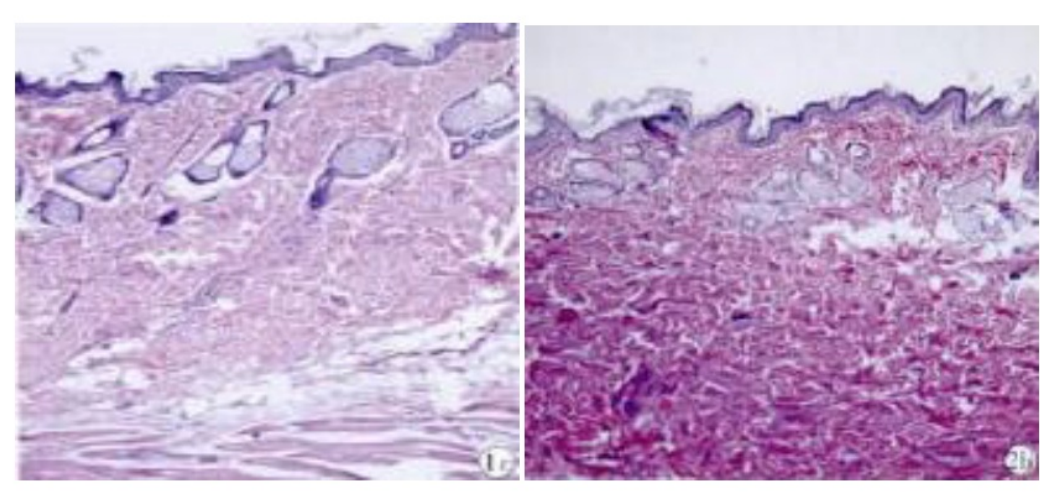

Low dose group

Medium dose group

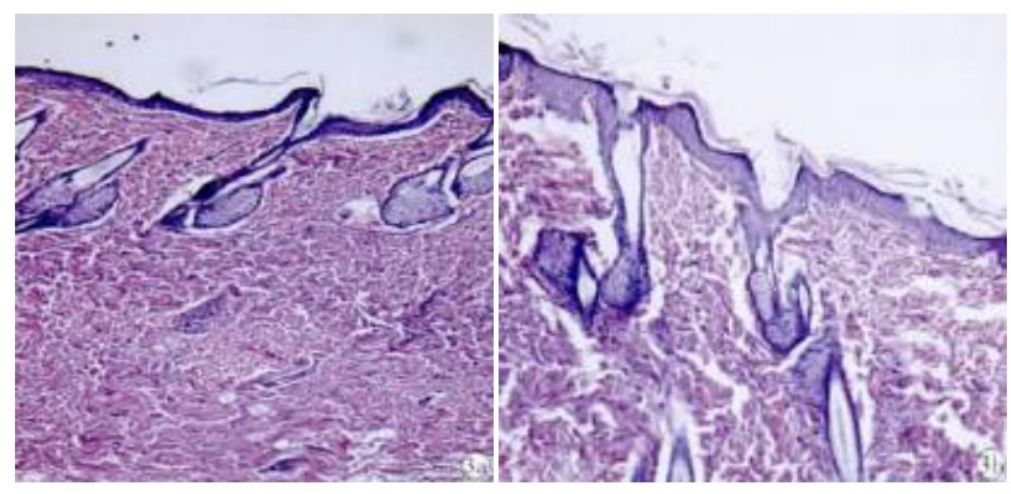

Positive control group

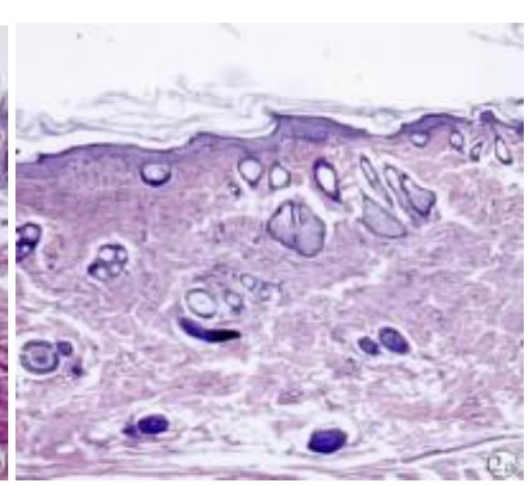

High dose group

Figure 3: Pathological sections of mice in each group $(H E \times 200)$.

\section{Effect on antibacterial experiment in vitro}

Bacteriostasis rate in each experimental group was shown in Table 5. Compared with low dose group, the high dose group had significant influence on the bacteriostasis effect of Staphylococcus aureus $(\mathrm{p}<0.05)$, in addition, the bacteriostasis rate of Escherichia coli medium in medium dose group and high dose group increased significantly $(\mathrm{p}<0.05)$ (Figure 4$)$. 

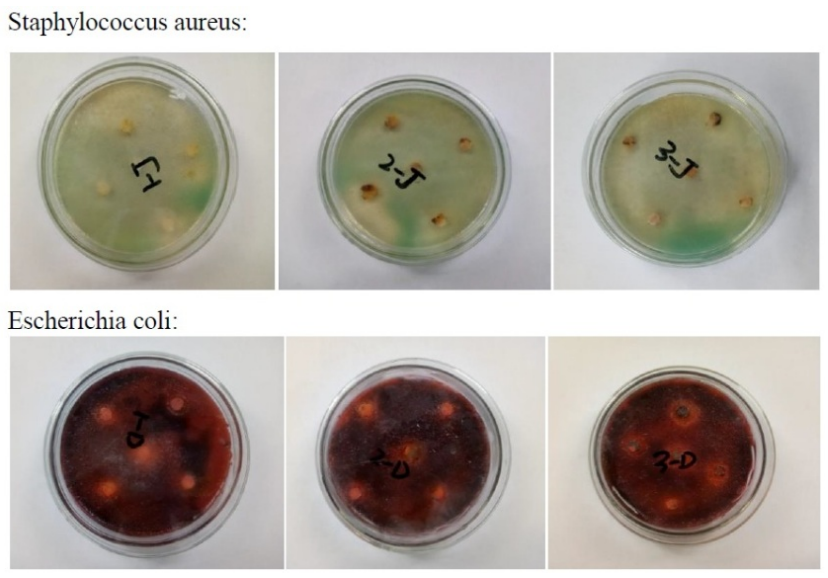

Figure 4: Bacteriostatic effect of Jinjianling cream.

DIZ and MIC of experimental group were shown in Table 6. The DIZ values of bacteriostatic circle on Staphylococcus aureus and Escherichia coli were $17.25 \mathrm{~mm}$ and $25.62 \mathrm{~mm}$, moreover, The MIC values of two kinds of bacteria all were 64 $\mathrm{ig} / \mathrm{mL}$. As shown in Figure 3, Jinjianling had the good bacteriostatic effect on two kinds of bacteria. It is noteworthy that the tolerance of Jinjianling cream on Escherichia coli was superior than that of Staphylococcus aureus, that may be due to the presence of double layer membrane structure in gram negative bacteria (E. coli) [7], that was more resistant to drug invasion than the monolayer structure of gram positive bacteria (Staphylococcus aureus).

Table 5: Bacteriostasis rate in each experimental group (Mean $\pm S D)$. ${ }^{*} p<0.05,{ }^{*} p<0.01$ compared with low dose group

\begin{tabular}{lll}
\hline Group & Escherichia coli (\%) & Staphylococcus aureus (\%) \\
\hline Low dose & $64.28 \pm 2.48$ & $64.54 \pm 3.66$ \\
\hline Medium dose & $76.47 \pm 0.87^{*}$ & $68.11 \pm 1.42$ \\
\hline High dose & $78.88 \pm 3.16^{*}$ & $83.32 \pm 1.54^{*}$ \\
\hline
\end{tabular}

Table 6: The DIZ and MIC values of two kinds bacteria (Mean $\pm S D)$.

\begin{tabular}{lll}
\hline Group & $\mathbf{D I Z}(\mathbf{m m})$ & $\mathbf{M I C}(\mathbf{i g} / \mathbf{m L})$ \\
\hline Escherichia coli & $17 \pm 1$ & 64 \\
\hline Staphylococcus aureus & $25 \pm 1$ & 64 \\
\hline
\end{tabular}

\section{Conclusion}

The wound will undergo a series of complicated reactions during recovery after the skin damaged, such as healing process and inflammatory reaction. Each process has a corresponding mechanism for regulation. Related studies show that, at the different stages of wound healing, the differences are mostly manifested in the changes of cytokines and metabolite levels $[8,9]$. Inflammatory reaction is considered to be an important step in the process of wound healing, which may delay wound healing [10]. Therefore, it is possible to regulate the inflammatory response by regulating the release of proinflammatory cytokines such as IL-1, TNF-a and IL-10
[11]. The results showed that the concentrations of IL-1, TNF-a and IL-2 increased after skin injury. After treatment, the above inflammatory factors decreased to some extent, indicating that the preparation seemed to prevent the over expression of inflammatory reaction and accelerate the formation of wound epithelium. There are a lot of pathogenic microbes on the surface of the skin. When the skin is damaged, the wound is easy to infect the pathogenic bacteria and affect the treatment [12].

Escherichia coli and Staphylococcus aureus are the most common pathogenic bacteria with the strong pathogenicity [13]. Antibacterial experiments found that Jinjianling cream had the stong inhibitory effect on pathogenic bacteria of wound, antibacterial ability was positively correlated with the concentration of drug, and the inhibition effect on Staphylococcus aureus was stronger than that of Escherichia coli. The aim of this study is to provide a safe and effective topical preparation for the treatment of common skin diseases such as dermatitis and eczema, we used the classic scald model and mouse ecazema model for the experiments. The preliminary results of experiments proved that Jinjianling cream could promote the healing of damaged skin and reduce the inflammatory reaction of wound. Its antibacterial activity was also proved by antibacterial experiment. In addition, we have conducted skin irritation experiments at the beginning of the experiment. The result of pre-experiment showed that Jinjianling cream had no irritation on the skin of mice, indicating that the preparation could be applied to human skin safely.

To sum up, this suggests that the Chinese medicine cream can be widely used in the prevention and treatment of traumatic inaction, can significantly improve wound healing, and further extended to the clinical treatment of dermatitis, eczema, psoriasis and other common skin diseases. The fundamental cause of inflammatory response is oxidative stress; inflammation is only one manifestation of the organism after oxidation [14]. Thus it can be seen that, there is a complex relation between inflammation oxidation in the body, this can serve as a new direction for our research.

\section{Acknowledgments}

We are profoundly grateful to the Innovation Practice Centre of Changchun University of Chinese Medicine for their technical support.

\section{Funding}

This research was supported by grants from the Chinese Medicine Health Food Science and Technology Innovation Centre of Jinlin Province.

\section{Availability of Data and Materials}

The datasets supporting the conclusions of this article are included within the article. 


\section{Author's Contributions}

ZW and YMM designed the experiments; QMY, MCX and GPH analyzed data; YMM, SS and ZDQ provided ideas of the research; YMM provided experiment condotins; ZW, QMY and LYT wrote the paper. ALL authors read and approve the final manuscript.

\section{Competing Interests}

The authors declare that there is no conflict of interest.

\section{Consent for Publication}

This information is not relevant.

\section{Ethics Approval}

The handle of experimental animals in the study was according to the Guide for the Care and Use of Laboratory Animal of the National Institute of Health as well as Guide of the Animal Welfare Act and approved by the Animal Ethics Committee of Changchun University of Chinese Medicine(approval No. SCXK 2017032).

\section{References}

1. Fry DE. Sepsis syndrome. Am Surg. 2000;66:126-132.

2. Gao XK, Nakamura N, Fuseda K, et al. Establishment of allergic dermatitis in $\mathrm{NC} / \mathrm{Ngamice}$ as a model for severe atopic dermatitis. Biol Pharm Bull. 2004;27(9):1376-1381.

3. Furue M, Furukawa F, Hide M, et al. Guidelines for therapy for atopic dermatitis. Jpn J Dermatol. 2004;114:135-142.

4. Kim SR, Choi HS, Seo HS, et al. Topical application of herbal mixture extract inhibits ovalbumin-or 2,4dinitrochlorobenzene-induced atopic dermatitis. J Evid Based Complementary Altern Med. 2012;2012:1-9.

5. Yum SJ, Kim SM, Yu YC, et al. Inhibition of growth and biofilm formation of Staphylococcus aureus by corosolic acid. Korean J. Food Sci. Technol. 2017;49(2):146-150.

6. Saha SK, Saha S, Akhter SM, et al. In Vitro Determination of Minimum Inhibitory Concentration of Aqueous Garlic
Extract and Imipenem against Staphylococcus aureus and Escherichia coli. Mymensingh Med J. 2016;25(3):477-484.

7. Zhao X. Hawk teaLitsea coreana Levl. Var. lanuginoseattenuates $\mathrm{CCl} 4$-induced hepatic damage in sprague-dawley rats. Exp Ther Med. 2012;5(2):555-560.

8. Schwacha MG. Macrophages and post-burn immune dysfunction. Burns. 2003;29(1):1-14.

9. Spyrou GN, Naylor IL. The effect of basic fibroblast growth factor on scarring. Br J Plast Surg. 2002;55(4): 275-282.

10. Arajo LU, Grabe-Guimares A, Mosqueira VC, et al. Profile of wound healing process induced by allantoin. Acta Cir Bras. 2010;25(5):460-461.

11. Dos LS, Marques FM, Vittorazzi C, et al. Struthanthus vulgaris ointment prevents an over expression of inflammatory response and accelerates the cutaneous wound healing. J Ethnopharmacol. 2016;190:319-327.

12. Lim K, Yoon C, Lee J. Antimicrobial Effect of Skin for Allograft and Management in Burn Wound. Open $\mathrm{J}$ of Organ Transplant Surgery. 2017;7(1):1-11.

13. Yagdiran Y, Talkyvist J, Artursson K, et al. Staphylococcus aureus and Lipopolysaccharide Modulate Gene Expressions of Drug Transporters in Mouse Mammary Epithelial Cells Correlation to Inflammatory Biomarkers. Plos One. 2016;11(9):e0161346.

14. Fu R, Zhang YT, Guo YR, et al. Antioxidant and antiinflammatory activities of the phenolic extracts of Sapium sebiferum (L.) Roxb. Leaves. J Ethnopharmacol. 2013;147(2):517-524.

\section{*Correspondence to:}

Ming-ming Yan

Changchun University of Chinese Medicine

Changchun 130117,

People's Republic of China

E-mail: 386759102@qq.com 